\title{
PROMOÇÃO DA APRENDIZAGEM SIGNIFICATIVA NO CONTEXTO DA SAÚDE, EDUCAÇÃO E CULTURA
}

\author{
PROMOCIÓN DE LA APRENDIZAJE SIGNIFICATIVO EN EL CONTEXTO DE LA \\ SALUD, EDUCACIÓN Y CULTURA
}

\author{
PROMOTING MEANINGFUL LEARNING IN THE CONTEXT OF HEALTH, \\ EDUCATION AND CULTURE
}

\author{
Micael Doria de ANDRADE ${ }^{1}$ \\ Rosangela Andrade Aukar de CAMARGO ${ }^{2}$
}

RESUMO: A Teoria da Aprendizagem Significativa propõe a construção de conhecimento por meio da valorização de experiências prévias dos alunos. Nesse sentido, objetivou-se relatar a promoção da aprendizagem significativa no contexto da saúde, educação e cultura a partir de manifestações artísticas. Trata-se de um relato de experiência sobre o Projeto de Intervenção Pedagógica "Café Literário: Jovens em Ação - Protagonistas da própria história", ocorrido entre fevereiro e maio de 2019 com estudantes do ensino médio regular de uma instituição pública da zona rural da Bahia, Brasil. A utilização da poesia, dramatização, dança e música como ferramentas pedagógicas instigou habilidades artísticas entre os estudantes, tornando-os protagonistas na construção de conhecimentos. Os alunos externaram seus anseios e perceberam o papel do professor como notável mediador neste processo. Evidenciou-se a importância da arte na promoção de aprendizagens significativas no contexto da saúde, educação e cultura.

PALAVRAS-CHAVE: Aprendizagem. Conhecimento. Arte. Estudantes. Adolescente.

RESUMEN: La teoría del aprendizaje significativo propone la construcción del conocimiento por medio de la valorización de experiencias previas de los estudiantes. El objetivo fue informar la promoción del aprendizaje significativo en el contexto de la salud, educación y cultura basadas en manifestaciones artísticas. Es un relato de experiencia sobre un Proyecto de Intervención Pedagógica, que ocorrió entre febrero y mayo de 2019 con estudiantes de una institución pública en el área rural de Bahía, Brasil. El uso de la poesía, dramatización, danza y música como herramientas pedagógicas instigó habilidades artísticas entre los estudiantes, convirtiéndolos en protagonistas en la construcción del conocimiento. Los estudiantes expresaron sus preocupaciones y se dieron cuenta del papel del maestro como un mediador notable. Se destacó la importancia del arte en la promoción del aprendizaje significativo en el contexto de la salud, educación y cultura.

PALABRAS CLAVE: Aprendizaje. Conocimiento. Arte. Estudiantes. Adolescente.

${ }^{1}$ Universidade Tiradentes (UNIT), Aracaju - SE - Brasil. Graduado em Letras Português/Espanhol. ORCID: https://orcid.org/0000-0001-9506-6704.E-mail: micaelandrade.unit@ hotmail.com

${ }^{2}$ Universidade de São Paulo (USP), Ribeirão Preto - SP - Brasil. Professora do Departamento de Enfermagem Materno-Infantil e Saúde Pública, Enfermeira e Pedagoga. Escola de Enfermagem de Ribeirão Preto (EERP-USP). Pós-Doutora (UALBERTA). ORCID: https://orcid.org/0000-0002-4872-2331. E-mail: rcamargo@ eerp.usp.br 
ABSTRACT: The Meaningful Learning Theory proposes the construction of knowledge by valuing students' previous experiences. The objective was to report the promotion of meaningful learning in the context of health, education and culture based on artistic manifestations. This is a report of experience about the Pedagogical Intervention Project "Literary Coffee: Adolescents in Action - Protagonists of their own history", which took place between February and May 2019 with high school students from a public institution in the rural area of Bahia, Brazil. The use of poetry, dramatization, dance and music as pedagogical tools instigated artistic skills among students, making them protagonists in the construction of knowledge. The students expressed their concerns and realized the role of the teacher as a notable mediator. It was evidenced the importance of art in promoting meaningful learning in the context of health, education and culture.

KEYWORDS: Learning. Knowledge. Art. Students. Adolescent.

\section{Introdução}

A Teoria da Aprendizagem Significativa foi proposta em 1963 pelo psicólogo educacional David Ausubel, sendo caracterizada pela construção de conhecimento a partir da valorização e resgate de experiências prévias dos alunos. A aprendizagem significativa ocorre quando a nova informação está ancorada em conceitos ou proposições relevantes e preexistentes na estrutura cognitiva do estudante (conceitos "subsunçores") (AGRA et al., 2019).

Essa aprendizagem é compatível com as concepções de Vygotsky, que considera a relação entre indivíduo e ambiente como principal meio para a construção do saber (RESENDE; SOUZA; RESENDE, 2017). Com apoio desta concepção, entende-se que a educação escolar é ainda uma das mais importantes formas de difusão do conhecimento, cujos pilares precisam ser significados e ressignificados por meio de aprendizagens significativas (SANTOS, 2019).

A educação escolar compreende 12 anos no sistema educacional básico dos Estados Unidos da América, correspondentes ao Ensino Fundamental e ao Ensino Médio do sistema educacional brasileiro. Todavia, ressalta-se que há uma gritante disparidade, em termos absolutos e relativos, no montante de recursos aplicados em educação entre esses dois países, sobretudo no âmbito profisssional (PERALTA; DIAS; GONÇALVES, 2018). Atrelado a este fato, a desigualdade social da maioria das famílias brasileiras reflete entraves na continuidade da escolarização no país, dentre outras implicações (DAYRELL; JESUS, 2016).

Independente destes condicionantes sociais, históricos e políticos nos diferentes sistemas educacionais, a adolescência deve ser vista primordialmente como uma das etapas decisivas no processo formativo do ser humano.

Sabe-se que o desenvolvimento saudável do adolescente diz respeito não somente à condição física ou ausência de problemas orgânicos, mas também aos aspectos psicológicos e 
socioambientais que o ajudam no enfrentamento de desafios. Não menos importante, considerase a cultura como agente que estreita laços entre a vida dos adolescentes e seus vínculos familiares, sociais e afetivos, uma vez que o contexto cultural e as suas manifestações influenciam no comportamento e na condição socioeducativa do indivíduo (RAMOS, 2018).

Frente a isso, ao observar os desafios que envolviam o desenvolvimento de aprendizagens significativas no contexto educacional, cultural e de saúde entre estudantes do ensino médio regular no interior do Nordeste brasileiro, realizou-se um projeto de intervenção pedagógica para evidenciar a possibilidade de promover aprendizagens significativas a partir de manifestações artísticas, usando a poesia, dramatização, dança e música como ferramentas pedagógicas para ressaltar o protagonismo do aluno neste processo (SOUSA et al., 2015).

O referencial teórico foi a Teoria da Aprendizagem Significativa, já que as atividades planejadas e desenvolvidas buscaram aproximar o conhecimento já existente às novas experiências propostas aos estudantes (MOREIRA, 2011).

Acredita-se que as ponderações e reflexões a seguir contribuem para potencializar o entendimento da prática docente mediante o desenvolvimento de um projeto de intervenção pedagógica para a promoção da aprendizagem significativa, tendo como público-alvo estudantes do ensino médio regular da rede pública. Portanto, objetivou-se relatar a promoção da aprendizagem significativa no contexto da saúde, educação e cultura a partir de manifestações artísticas

\section{Procedimentos metodológicos}

O presente estudo descritivo consiste em um relato de experiência sobre o Projeto de Intervenção Pedagógica intitulado "Café Literário: Jovens em ação - Protagonistas da própria história", ocorrido entre fevereiro e maio de 2019.

O Café Literário foi realizado em uma instituição pública de ensino médio regular, localizada em "Lagoa Redonda", distrito interiorano/zona rural do município Itapicuru, Bahia, Brasil.

Segundo dados disponibilizados pela Secretaria de Desenvolvimento Social de Itapicuru, em 2019, "Lagoa Redonda” possuía um total de 8.230 habitantes. É valido evidenciar que, Lagoa Redonda preserva poucas manifestações artístico-culturais, mas ainda assim, próprias do interior nordestino, tais como: festejos de santos padroeiros, concurso de quadrilhas juninas, procissões e celebrações religiosas. Essas realizações, basicamente, suprem a 
necessidade de atividades culturais da população, pois em virtude de maiores investimentos, outros subsídios culturais não são ofertados.

A direção escolar da instituição de ensino na qual o Café Literário foi realizado informou que o colégio foi fundado em 2014, e atende, atualmente, cerca de 500 alunos do ensino médio, tanto da própria localidade como de povoados e lugarejos adjacentes. A maioria é de baixa renda e seus grupos familiares são beneficiados por programas governamentais, sobretudo o Bolsa Família. O cenário atual da instituição escolar pode ser definido como desafiador, já que não há saneamento básico, vias pavimentadas e rede de esgoto.

Em relação ao planejamento do Café Literário, ainda no início do ano letivo, no encontro pedagógico, o projeto foi idealizado pelo primeiro autor do presente estudo/docente na área de linguagens e apresentado à equipe diretiva e coordenação do colégio, a fim de assegurar sua inserção no calendário escolar, bem como para tornar claro os objetivos e o processo de desenvolvimento das atividades.

Um dos desafios foi adequar o cronograma do projeto sem interferir nas atividades pedagógicas e no planejamento da equipe. Por outro lado, houve o incentivo e apoio por parte dos demais professores e da equipe gestora. Assim, o Café Literário aconteceu concomitantemente às atividades existentes no currículo anual e grade curricular, respeitando e não interrompendo o aproveitamento e rendimento dos alunos, sendo, portanto, um trabalho que vislumbrou a participação direta e indireta de outras áreas de conhecimento numa transversalidade conjunta.

Em seguida, especificamente na primeira semana de aula, todas as 11 (onze) turmas da $1^{\mathrm{a}}, 2^{\mathrm{a}}$ e $3^{\mathrm{a}}$ séries do ensino médio, nos turnos matutino e vespertino - sendo duas da $1^{\mathrm{a}}$ série matutina $\left(1^{\mathrm{a}} \mathrm{A} / \mathrm{M}\right.$ e $\left.1^{\mathrm{a}} \mathrm{B} / \mathrm{M}\right)$; duas da $1^{\mathrm{a}}$ série vespertina $\left(1^{\mathrm{a}} \mathrm{A} / \mathrm{V}\right.$ e $\left.1^{\mathrm{a}} \mathrm{B} / \mathrm{V}\right)$; duas da $2^{\mathrm{a}}$ série matutina $\left(2^{\mathrm{a}} \mathrm{A} / \mathrm{M}\right.$ e $\left.2^{\mathrm{a}} \mathrm{B} / \mathrm{M}\right)$; duas da $2^{\mathrm{a}}$ série vespertina $\left(2^{\mathrm{a}} \mathrm{A} / \mathrm{V}\right.$ e $\left.2^{\mathrm{a}} \mathrm{B} / \mathrm{V}\right)$; duas da $3^{\mathrm{a}}$ série matutina ( $3^{\mathrm{a}} \mathrm{A} / \mathrm{M}$ e $\left.3^{\mathrm{a}} \mathrm{B} / \mathrm{M}\right)$ e uma turma da $3^{\mathrm{a}}$ série vespertina $\left(3^{\mathrm{a}} \mathrm{A} / \mathrm{V}\right)$ - foram informadas pelo professor da área de linguagens que o projeto seria desenvolvido.

Por sua vez, evidenciou-se os pormenores e características do Café Literário, apresentando os objetivos, métodos e atividades a serem desenvolvidas nos meses seguintes, em conformidade com os conhecimentos de língua portuguesa, literatura e produção textual. Assim, os estudantes souberam antecipadamente que o projeto se debruçava no campo artístico, literário e cultural e que seriam instigados a explorar a criatividade em busca do alcance da valorização do protagonismo juvenil.

Neste aspecto, os discentes tiveram que formar grupos e trabalhar em parceria com os colegas para produzirem peças teatrais, coreografias, recitais de poemas ou literaturas de 
cordéis, bem como cantarem músicas MPB ou paródias que dialogassem com a temática proposta no Café Literário. Isso permitiu traçar a visão dos alunos sobre o autoconceito artístico no âmbito da arte, sendo este um construto da multidimensionalidade interligado ao saber (PIPA; PEIXOTO, 2014).

As vertentes artísticas utilizadas foram a poesia, a dramatização, a dança e a música, tendo a área de linguagens como base para a idealização das atividades, conforme descrição a seguir:

A) POESIA - As poesias produzidas deveriam ser inéditas, respeitando as características do gênero textual poema ou literatura de cordel, contendo rimas, versos, estrofes, musicalidade e uma linguagem literária. Sendo em grupo ou individual, as poesias precisavam, acima de tudo, promover uma reflexão acerca da importância e/ou valorização dos jovens e/ou enfrentamento dos problemas do cotidiano, oferecendo para o ouvinte uma motivação diante das dificuldades. O tempo estimado para a recitação do poema ficou pautado entre três e cinco minutos por produção, fosse coletivo ou individualizado.

B) DRAMATIZAÇÃO - Nesta atividade, que foi desenvolvida unicamente em grupos, entre cinco e dez minutos, os alunos utilizaram da teatralidade para encenar as diversas formas de como os jovens podem estar em ação numa sociedade rodeada de desafios. Com subtemas livres, dentro da temática central do projeto, os estudantes encenaram em torno de problemáticas como: depressão, automutilação, ansiedade, gravidez na adolescência, abuso sexual, bullying, rejeição familiar e preconceito relacionado à orientação sexual de gays e lésbicas no meio social.

C) DANÇA - No que diz respeito à coreografia, os alunos tiveram a oportunidade em grupos ou em apresentações solo de mostrar como os movimentos corporais seriam capazes de expressar as angústias, sofrimento, alegrias e superação que muitos vivenciam. Com músicas nacionais, internacionais ou instrumentais, cada grupo e/ou aluno permitiu que a arte da dança falasse com gestos corporais o que o(s) incomodava socialmente, diante de cada anseio ou inquietação vivenciada. As coreografias foram estipuladas em apresentações curtas de três a cinco minutos no máximo.

D) MÚSICA/CANÇÃO - Nesta modalidade, os estudantes também puderam se dividir em grupos ou individualmente, em até quatro minutos. O critério desta atividade consistiu em respeitar e obedecer ao gênero MPB, fosse para criar paródias ou cantar músicas do repertório nacional. As canções entoadas deveriam promover uma análise do contexto político-social, trazendo como plano de fundo desafios do mundo dos jovens. 
As atividades mencionadas acima foram preparadas e desenvolvidas entre os meses de fevereiro e maio de 2019. Os alunos sob a orientação do professor-orientador produziram as manifestações artísticas de acordo com o tema central do projeto, ou seja, jovens em ação, sendo estes protagonistas da própria história.

Nas primeiras semanas dos meses de fevereiro e março, as aulas de linguagem do docente responsável foram abertas parcialmente para discussões em grupos sobre as atividades, além disso, em cada turma das séries contempladas, o professor procurou, na etapa inicial, identificar quais os subtemas, ideias ou possíveis dúvidas que os alunos poderiam ter, com isso, buscou-se em todas as aulas investigar o que os grupos já haviam pesquisado e, através de rodas de conversas, os envolvidos expunham suas descobertas em um bate-papo intermediado pelo professor.

Ainda neste processo, foi elaborada uma ficha de identificação para cada grupo ou aluno com apresentação solo, com o objetivo de acompanhar os discentes e observar a descrição do que eles estavam desenvolvendo ou pretendiam idealizar durante a fase de preparação do Café Literário.

O primeiro bimestre (fevereiro e março) foi fundamental para diagnosticar quais as necessidades dos alunos diante de suas apresentações vindouras, permitindo, assim, uma agilidade em providenciar junto à coordenação materiais e recursos que seriam utilizados na fase final do projeto, a exemplo: som, tecidos, tintas, papéis, cenários, entre outros.

É válido mencionar que, mesmo diante de toda a preparação do projeto, os conteúdos da grade curricular de cada série/turma não foram prejudicados, pois as discussões e orientações mediadas entre professor e aluno ocorreram nos momentos finais de cada encontro, assim, além de seguir o plano de aula convencional, também foi possível, paralelamente, dar uma atenção às atividades do Café Literário.

Após o processo de idealização das ideias em cada modalidade artística, todos os grupos foram incentivados a usarem os meses subsequentes (abril e maio) para realizar ensaios semanais que aprimorassem as apresentações, deste modo, tornou-se consensual entre professor e discentes que, dos cinquenta minutos de cada aula, os vinte minutos finais seriam reservados para ensaios. Nesta fase, os alunos usaram os espaços improvisados que estavam à disposição no colégio, como pátio, corredores, sala de informática, biblioteca ou até mesmo sombra de árvore, pois em virtude de a instituição pertencer à zona rural, ainda detém um espaço limitado como auditório e/ou salão de dança.

Diante de toda a preparação e como já era de conhecimento dos alunos, no último dia letivo do mês de maio, 29/05/2019, ocorreu o encerramento do projeto. Todas as turmas 
ansiavam para expor suas apresentações no pátio central do colégio. Cabe lembrar que, este espaço - palco dos jovens em ação - foi previamente ornamentado com a ajuda dos estudantes. Neste local foram exibidos painéis, cartazes e ilustrações que faziam alusão ao tema central do projeto, bem como frases e expressões colhidas nos debates em sala de aula, evidenciando, desta forma, que as ideias e sugestões emitidas pelos alunos tinham sido acatadas e ganhavam vida até mesmo na decoração do ambiente.

Assim, tanto no turno matutino como no vespertino, as apresentações ocorreram conforme planejado, em ordem sequenciada da $1^{\mathrm{a}}$ a $3^{\mathrm{a}}$ séries do ensino médio, obedecendo as seguintes modalidades artísticas: poesias, dramatizações, danças e músicas, cabendo ao professor-orientador convidar de forma organizada cada grupo ou aluno mediante a ordem de apresentação.

Além dos próprios alunos prestigiarem o talento um dos outros, também foram espectadores alguns pais, demais professores da instituição, funcionários de apoio do colégio e até ex-alunos, que ao saberem do evento para finalização do Café Literário, sentiram-se interessados em assistir as apresentações.

Vale ressaltar que, nesse texto, descreveu-se apenas o desenvolvimento de atividades pedagógicas em uma escola de ensino médio onde o autor principal leciona, sem a realização de nenhum tipo de procedimento ou intervenção com fins de pesquisa científica. Trata-se de um aprofundamento teórico de situações que emergem espontaneamente da prática pedagógica exercida.

\section{Resultados e discussões}

Considerando a realidade e o contexto social no qual os estudantes alvos do projeto estão inseridos, observou-se que a realização do Café Literário proporcionou aos envolvidos uma oportunidade de vivenciar e aprimorar novas experiências educacionais, que resultaram numa aprendizagem significativa, dinâmica, interativa e sociocultural, promovendo o bem-estar e, consequentemente, promovendo saúde. Assim, buscou-se tornar o ambiente escolar um fomentador de aprendizagens significativas, democratizando o acesso ao saber (TEDESCO; REBELATTO, 2015).

É pertinente esclarecer que o "lócus" no qual estão inseridos, seja a escola ou a própria comunidade, distancia os estudantes de políticas públicas eficazes, o que automaticamente gera empecilhos para professores e discentes na adesão de práticas culturais e artísticas, pois como se trata de uma localidade interiorana (rural), a presença de espaços que ofereçam cinema, 
teatro, dança, música e outras vivências artístico-culturais ainda são muito escassos. Acreditase que, quando isso não é balanceado, há a possibilidade de influenciar negativamente em inovações que poderiam resultar em condições favoráveis para educação e/ou cultura.

Tal situação revela a necessidade do projeto Café Literário ter sido realizado nessa comunidade, pois, por meio de suas atividades, aproximou os alunos a uma realidade pouco ofertada para eles.

A escolha da temática ocorreu em virtude da necessidade dos alunos se sentirem valorizados mediante suas condições psicossociais, já que muitos dos jovens encontravam-se desestimulados em relação ao reconhecimento de sua função social dentro e fora do ambiente escolar, tornando-os vulneráveis socialmente, ou seja, sujeitos expostos à incidência de riscos em fatores éticos políticos e técnicos que possam comprometer a capacidade humana para o seu enfrentamento (CARMO; GUIZARDI, 2018).

Cabe ressaltar que, ampliar o conhecimento de estudantes é um desafio constante, porém, torna-se ainda mais prazeroso quando estes se tornam protagonistas de suas realizações e essas extrapolam a sala de aula, pois, quando o foco é assegurar uma aprendizagem significativa, é importante que todos, no ambiente escolar, considerem as diversas áreas da educação como uma forma de articular múltiplos elementos sociais, culturais e singulares que também resultem no bem-estar dos discentes, intensificando a promoção do ensinoaprendizagem (NEVES, 2017).

Ao acompanhar os desafios educacionais que o colégio e a comunidade vivenciam, como a ausência de políticas púbicas que ofertem subsídios materiais e culturais, tornou-se perceptível, ainda assim, o alcance de uma aprendizagem significativa na prática profissional, ampliando valores necessários ao trabalho docente e assegurando a empatia nos alunos, mesmo diante deste cenário de dificuldades (NALOM et al., 2019).

Logo, torna-se claro que, a partir da união entre perspectivas da educação, saúde e cultura, os estudantes puderam vivenciar na prática o conhecimento que eles detinham de modo internalizado, sendo este atrelado às práticas artísticas e manifestado nas diversas modalidades (poesia, teatro, dança ou música), ou seja, notou-se um conhecimento sociointeracionista que procurou abordar os saberes prévios dos educandos, bem como uma atitude problematizadora visando uma produção crítica e reflexiva.

Neste sentido, é importante destacar que o empenho em tais atividades explorou a capacidade interpretativa dos discentes, promovendo uma otimização da leitura, escrita e expressividade da oralidade, além de movimentos da linguagem corporal através das artes cênicas e coreografias, permitindo uma aprendizagem regada de significados e sentidos, já que 
a união do conhecimento de mundo dos estudantes somado às práticas empíricas e sistematizadas favoreceu a aprendizagem significativa mediante necessidades dos grupos sociais e dos seus enfrentamentos (PAVAN, 2016).

No que diz respeito ao contato dos alunos com novas experiências, promovidas pelo Café Literário, constatou-se que todas as turmas desenvolveram um processo de aprendizagem contínuo, participativo e interativo, baseado nos preceitos do ensino-aprendizagem.

Nesta perspectiva, os estudantes criaram um senso de responsabilidade ainda mais eficiente, pois tiveram que ser ativos em busca do conhecimento, assumir liderança de grupos, desenvolver a autonomia da aprendizagem e organizar leituras que embasassem as atividades propostas, ou seja, desenvolveram estratégias inovadoras fortalecendo as concepções de educação problematizadora e aprendizagem significativa (MACEDO et al., 2018).

É evidente que eles também manifestaram um espírito de união entre os colegas, já que ao passo que questionavam entre si ou se encontravam para ensaios e discussões, o entrosamento e a dinâmica de grupo eram reforçados.

Também se tornou perceptível que a interação entre professor-aluno foi alcançada. A mediação do conhecimento no processo de concretização desse projeto permitiu que o docente agisse como mediador, levando os alunos a serem os principais agentes na construção do conhecimento dentro e fora da sala de aula (ALTET, 2017).

Logo, torna-se claro que a realização desse projeto de intervenção ocorreu em virtude da necessidade de os alunos se sentirem valorizados e autônomos, mediante suas condições psicossociais, socioculturais e socioeducativas, já que muitos dos jovens encontravam-se desestimulados em relação ao reconhecimento de sua função como sujeitos ativos e participativos no processo de significação e ressignificação de sua aprendizagem, dentro e fora do ambiente escolar.

Entende-se que este projeto fomentou nos estudantes a promoção da saúde através da capacidade de superação da vulnerabilidade social, instigando nestes o enfrentamento de problemáticas e alternativas para contornar as dificuldades enfrentadas e superar as fragilidades que os cercam (CARMO; GUIZARDI, 2018).

Destaca-se que a escola, mesmo não sendo um centro terapêutico especializado, não pode negar o contexto emocional dos alunos (ABED, 2014). Por meio deste trabalho, buscouse estar atento às emoções, sensações, sentimentos, pensamentos e ações dos estudantes.

Para tanto, as ponderações destas discussões tomaram como subsídio principal o embasamento teórico e os conceitos da aprendizagem significativa do estudioso David Ausubel. Este, em suas concepções no campo da Psicopedagogia, versa que a aprendizagem significativa, 
enquanto construção cognitiva, ocorre quando há interação de novas informações com o conhecimento que o sujeito traz consigo, seja esse social, histórico, emocional ou artístico (DISTLER, 2015).

É notável também considerar que o presente trabalho se valeu da participação suscita das contribuições de Marco Antônio Moreira, professor e investigador de renome nacional. Este preserva a origem da aprendizagem significativa, mas também amplia seu conceito, associando o ensino desse tipo de aprendizagem como um ato organizado para proporcionar aos estudantes experiências positivas, já que estes, como seres humanos, estão integrados na aprendizagem através de pensamentos, sentimentos e ações (MOREIRA, 2017).

\section{Considerações finais}

O presente estudo descreveu o processo e os resultados advindos do "Café Literário: Jovens em ação - Protagonistas da própria história", que possibilitou a promoção de aprendizagens significativas a partir de manifestações artísticas entre estudantes do ensino médio regular, usando a poesia, dramatização, dança e música como ferramentas pedagógicas para ressaltar o protagonismo do aluno neste processo.

Os alunos puderam se reconhecer como sujeitos ativos e responsáveis em suas conquistas e realizações, pois perceberam que são capazes de converter uma realidade desafiante em motivações, através de suas produções, sejam essas no alcance do conhecimento formal, em sala de aula, ou no processo de autoconhecimento como um cidadão capaz de enxergar-se em meio à sociedade.

Notou-se que a aprendizagem significativa foi potencializada por meio da relação professor-aluno e, como resultado disso, observou-se a efetivação de todas as atividades propostas. Os alunos compreenderam que o processo de valorização do conhecimento deve ser contínuo, compartilhado e associado à realidade que os circundam.

Além disso, usando o suporte artístico, o Café Literário se apropriou da arte como ferramenta pedagógica para instigar alunos do ensino médio a explorarem suas capacidades no âmbito de criações artísticas, dialogando com a base curricular de produções textuais no campo da literatura. O colégio tornou-se palco de atividades que permitiram tanto à equipe docente, e principalmente, aos discentes, refletirem sobre a função da educação escolar em suas vidas.

Houve a descoberta de novos talentos nos mais diversos campos artísticos por parte dos alunos. Muitos se reconheceram diante de suas habilidades como poetas, dançarinos, cantores 
e atores. Isso favoreceu o processo de reconhecimento de identidade do indivíduo, fomentando o desejo de aprimorar essas descobertas como áreas profissionais.

É relevante pontuar que muitos estudantes também evidenciaram suas emoções durante as atividades realizadas, deixando de lado aspectos da timidez, que antes eram encarados como problemas na socialização e realização de trabalhos em grupo, dentro e fora da sala de aula.

No que diz respeito à saúde, percebeu-se que as atividades ajudaram os alunos a externar seus desconfortos e anseios, pois como a temática estava associada "aos jovens em ação protagonistas da própria história”, muitos deles trouxeram para as produções suas realidades de conflitos internos, dúvidas e ansiedades. Alguns, por meio da poesia, retrataram sofrer depressão, bullying e até abusos sexuais.

Logo, conhecendo as dificuldades e problemas que determinados alunos enfrentavam, o colégio teve o cuidado de aproximar-se ainda mais desses jovens, em busca de procurar ajuda, fosse por meio da família ou instituições que garantissem um acompanhamento mais especializado para cada caso/situação.

Evidencia-se também o papel do professor como mediador do conhecimento e incentivador de uma aprendizagem significativa. Além de usar todas as atividades como um processo de avaliação contínua no processo da aprendizagem dos estudantes, o professororientador do Café Literário conseguiu converter atividades interdisciplinares para área de linguagens, promovendo desta forma um conhecimento não fragmentado e isolado, mas que dialogasse com o mundo artístico, através das diversas produções dos alunos, na poesia, dança, música e teatro. Por conta disso, foi observado também que muitos estudantes desenvolveram interesse pelo mundo da literatura e da escrita autoral de poemas.

Portanto, os resultados deste trabalho são positivos, pois a aprendizagem significativa foi promovida/alcançada e os estudantes reconheceram-se como "jovens em ação", que acima de tudo, podem ser encarados como "protagonistas da própria história”. Ademais, o ambiente escolar e a comunidade à sua volta conseguiram perceber o potencial dos estudantes, permitindo valorizá-los ainda mais, independente da ausência de ações de determinadas políticas públicas nacionais.

\section{REFERÊNCIAS}

ABED, A. L. Z. O desenvolvimento das habilidades socioemocionais como caminho para a aprendizagem e o sucesso escolar de alunos da educação básica. São Paulo: MEC, 2014. 
AGRA, G. et al. Análise do conceito de Aprendizagem Significativa à luz da Teoria de Ausubel. Rev. Bras. Enferm., Brasília, v. 72, n. 1, p. 248-255, 2019. Disponível em: http://www.scielo.br/pdf/reben/v72n1/pt_0034-7167-reben-72-01-0248.pdf. Acesso em: 20 mar. 2020. DOI: https://doi.org/10.1590/0034-7167-2017-0691

ALTET, M. A observação das práticas de ensino efetivas em sala de aula: pesquisa e formação. Cad. Pesqui., São Paulo, v. 47, n. 166, p. 1196-1223, 2017. Disponível em: http://www.scielo.br/pdf/cp/v47n166/1980-5314-cp-47-166-1196.pdf. Acesso em: 20 mar. 2020. DOI: https://doi.org/10.1590/198053144321

CARMO, M. E.; GUIZARDI, F. L. O conceito de vulnerabilidade e seus sentidos para as políticas públicas de saúde e assistência social. Cad. Saúde Pública, Rio de Janeiro, v. 34, n. 3, 2018. Disponível em: http://www.scielo.br/pdf/csp/v34n3/1678-4464-csp-34-03e00101417.pdf. Acesso em: 20 mar. 2020. DOI: https://doi.org/10.1590/0102-311x00101417.

DAYRELL, J. T.; JESUS, R. E. Juventude, ensino médio e os processos de exclusão escolar. Educ. Soc., Campinas, v. 37, n. 135, p. 407-423, 2016. Disponível em: http://www.scielo.br/pdf/es/v37n135/1678-4626-es-37-135-00407.pdf. Acesso em: 20 mar. 2020. DOI: https://doi.org/10.1590/ES0101-73302016151533

DISTLER, R. R. Contribuições de david ausubel para a intervenção psicopedagógica. Rev. psicopedag., São Paulo, v. 32, n. 98, p. 191-199, 2015. Disponível em: http://pepsic.bvsalud.org/pdf/psicoped/v32n98/09.pdf. Acesso em: 20 mar. 2020.

MACEDO, K. D. S. et al. Metodologias ativas de aprendizagem: caminhos possíveis para inovação no ensino em saúde. Esc Anna Nery, Rio de Janeiro, v. 22, n. 3, p. 1-9, 2018. Disponível em: http://www.scielo.br/pdf/ean/v22n3/1414-8145-ean-22-03-e20170435.pdf. Acesso em: 20 mar. 2020. DOI: https://doi.org/10.1590/2177-9465-ean-2017-0435

MOREIRA, M. A. Aprendizagem significativa: a teoria e textos complementares. São Paulo: Editora Livraria da Física, 2011.

MOREIRA, M. A. Aprendizaje significativo como un referente para la organización de la enseñanza. Archivos de Ciencias de la Educación, Buenos Aires, v. 11, n. 12, 2017. Disponível em: https://www.archivosdeciencias.fahce.unlp.edu.ar/article/view/Archivose029. Acesso em: 20 mar. 2020. DOI: https://doi.org/10.24215/23468866e029

NALOM, D. M. F. et al. Ensino em saúde: aprendizagem a partir da prática profissional. Ciênc. saúde coletiva, Rio de Janeiro, v. 24, n. 5, p. 1699-1708, 2019. Disponível em: http://www.scielo.br/pdf/csc/v24n5/1413-8123-csc-24-05-1699.pdf. Acesso em: 20 mar. 2020. DOI: https://doi.org/10.1590/1413-81232018245.04412019

NEVES, L. R. Contribuições da Arte ao Atendimento Educacional Especializado e à Inclusão Escolar. Rev. bras. educ. espec., Bauru, v. 23, n. 4, p. 489-504, 2017. Disponível em: http://www.scielo.br/pdf/rbee/v23n4/1413-6538-rbee-23-04-0489.pdf. Acesso em: 20 mar. 2020. DOI: http://dx.doi.org/10.1590/S1413-65382317000400002.

PAVAN, F.C. Diversidade Cultural e Aprendizagem Significativa na Construção da Cidadania. Revista Científica Multidisciplinar Núcleo do Conhecimento, São Paulo, v. 9, n. 1, p. 632-647, 2016. Disponível em: 
https://www.nucleodoconhecimento.com.br/educacao/diversidade-cultural-e-aprendizagemsignificativa-na-construcao-da-cidadania. Acesso em: 20 mar. 2020.

PERALTA, D. A.; DIAS, A. L. B.; GONÇALVES, H. J. L. Educação Profissional nos EUA: traços históricos, legais e curriculares. Educ. Real., Porto Alegre, v. 43, n. 3, p. 969-987, 2018. Disponível em: http://www.scielo.br/pdf/edreal/v43n3/2175-6236-edreal-43-03969.pdf. Acesso em: 20 mar. 2020. DOI: https://doi.org/10.1590/2175-623666866

PIPA, J.; PEIXOTO, F. Tipo de ensino e autoconceito artístico de adolescentes. Estud. psicol., Campinas, v. 31, n. 2, p. 159-167, 2014. Disponível em:

http://www.scielo.br/pdf/estpsi/v31n2/a02v31n2.pdf. Acesso em: 20 mar. 2020. DOI: http://dx.doi.org/10.1590/0103-166X2014000200002

RAMOS, F.C. Socialização e cultura escolar no Brasil. Rev. Bras. Educ., Rio de Janeiro, v. 23, p. 1-21, 2018. Disponível em: http://www.scielo.br/pdf/rbedu/v23/1809-449X-rbedu-23e230006.pdf. Acesso em: 20 mar. 2020. DOI: http://dx.doi.org/10.1590/S141324782018230006

RESENDE, T. R. P. S.; SOUZA, I. A.; RESENDE, G. S. L. Vygotsky: uma base teórica para a proposta do ensino por meio de ciclos. Rev. Edu. e Emancip., São Luís, v. 10, n. 3, p. 195216, 2017. Disponível em:

http://www.periodicoseletronicos.ufma.br/index.php/reducacaoemancipacao/article/view/772 3. Acesso em: 20 mar. 2020. DOI: http://dx.doi.org/10.18764/2358-4319.v10n3p195-216

SANTOS, E. A educação como direito social e a escola como espaço protetivo de direitos: uma análise à luz da legislação educacional brasileira. Educ. Pesqui., São Paulo, v. 45, p. 115, 2019. Disponível em: http://www.scielo.br/pdf/ep/v45/1517-9702-ep-45-e184961.pdf. Acesso em: 20 mar. 2020. DOI: https://doi.org/10.1590/s1678-4634201945184961

SOUSA, A. T. O. et al. A utilização da teoria da aprendizagem significativa no ensino da Enfermagem. Rev. Bras. Enferm., Brasília, v. 68, n. 4, p. 713-22, 2015. Disponível em: http://www.scielo.br/pdf/reben/v68n4/0034-7167-reben-68-04-0713.pdf. Acesso em: 20 mar. 2020. DOI: http://dx.doi.org/10.1590/0034-7167.2015680420i

TEDESCO, A. L.; REBELATTO, D. M. B. Qualidade social da educação: um debate em aberto. Perspect em Políticas Públicas, Minas Gerais, v. 8, n. 16, p. 173-19, 2015. Disponível em: http://revista.uemg.br/index.php/revistappp/article/view/1020. Acesso em: 20 mar. 2020. 


\section{Como referenciar este artigo}

ANDRADE, Micael Doria de; CAMARGO, Rosangela Andrade Aukar de. Promoção da Aprendizagem Significativa no contexto da Saúde, Educação e Cultura. Temas em Educ. e Saúde, Araraquara, v. 16, n. 1, p. 201-214, jan./jun., 2020. e-ISSN 2526-3471. DOI: https://doi.org/10.26673/tes.v16i1.13469

Submetido em: 21/03/2020

Revisões requeridas: 06/06/2020

Aprovado em: 12/06/2020

Publicado em: 19/06/2020 